\title{
Article \\ Opioid Prescription Following Wrist and Ankle Fracture Fixation in Scotland-Tradition Prevails
}

\author{
William T. Gardner 1,*(D), David R. W. MacDonald ${ }^{1,2}$, Matthew J. Kennedy ${ }^{3,4}$, Alastair C. Faulkner ${ }^{5}$, \\ Joshua R. McIntyre ${ }^{6}$, Patrice Forget ${ }^{7,8} \mathbb{D}$, Stuart A. Aitken ${ }^{9}$, Iain M. Stevenson ${ }^{1}$ \\ and on behalf of the SCORE Collaborative ${ }^{\dagger}$
}

check for updates

Citation: Gardner, W.T.; MacDonald, D.R.W.; Kennedy, M.J.; Faulkner, A.C.; McIntyre, J.R.; Forget, P.; Aitken, S.A.; Stevenson, I.M.; on behalf of the SCORE Collaborative. Opioid Prescription Following Wrist and Ankle Fracture Fixation in Scotland-Tradition Prevails. J. Clin. Med. 2022, 11, 468. https://doi.org/ $10.3390 /$ jcm 11020468

Academic Editors: Daniel Pecos-Martín, Deborah Falla and Giustino Varrassi

Received: 21 November 2021

Accepted: 10 January 2022

Published: 17 January 2022

Publisher's Note: MDPI stays neutral with regard to jurisdictional claims in published maps and institutional affiliations.

Copyright: (c) 2022 by the authors Licensee MDPI, Basel, Switzerland. This article is an open access article distributed under the terms and conditions of the Creative Commons Attribution (CC BY) license (https:// creativecommons.org/licenses/by/ $4.0 /)$
1 Department of Trauma \& Orthopedics, Aberdeen Royal Infirmary, Aberdeen AB25 2ZN, UK; david.macdonald7@nhs.scot (D.R.W.M.); iain.stevenson@nhs.scot (I.M.S.)

2 Department of Trauma \& Orthopedics, Raigmore Hospital, Inverness IV2 3UJ, UK

3 Department of Trauma \& Orthopedics, Queen Elizabeth University Hospital, Glasgow G51 4TF, UK; mjkennedy92@gmail.com

4 Department of Trauma \& Orthopedics, Royal Alexandra Hospital, Paisley PA2 9PJ, UK

5 Department of Trauma \& Orthopedics, Ninewells Hospital, Dundee DD2 1SG, UK; alastair.faulkner@nhs.scot

6 Department of Trauma \& Orthopedics, Royal Infirmary of Edinburgh, Edinburgh EH16 4SA, UK; joshua.mcintyre@nhslothian.scot.nhs.uk

7 Department of Anaesthesia, NHS Grampian, Aberdeen AB25 2ZD, UK; patrice.forget@abdn.ac.uk

8 Epidemiology Group, Institute of Applied Health Sciences, School of Medicine, Medical Sciences and Nutrition, University of Aberdeen, Aberdeen AB25 2ZD, UK

9 Department of Trauma \& Orthopedics, MaineGeneral Hospital, Augusta, ME 04330, USA; saaitken@me.com

* Correspondence: tim.gardner@nhs.scot

+ Membership of the Score Collaborators is provided in the Supplementary Material.

\begin{abstract}
The American 'opioid crisis' is rapidly spreading internationally. Perioperative opioid use increases the risk of long-term opioid use. We review opioid use following wrist and ankle fracture fixation across Scotland, establishing prescribing patterns and associations with patient, injury, or perioperative factors. Six Scottish orthopedic units contributed. A total of 598 patients were included. Patient demographics were similar across all sites. There was variation in anesthetic practice, length of stay, and AO fracture type $(p<0.01)$. For wrist fractures, $85.6 \%$ of patients received a discharge opioid prescription; $5.0 \%$ contained a strong opioid. There was no significant variation across the six units in prescribing practice. For ankle fractures, $82.7 \%$ of patients received a discharge opioid prescription; $17 \%$ contained a strong opioid. Dundee and Edinburgh used more strong opioids; Inverness and Paisley gave the least opioids overall $(p<0.01)$. Younger patient age, location, and length of stay were independent predictors of increased prescription on binary regression. Despite variability in perioperative practices, discharge opioid analgesic prescription remains overwhelmingly consistent. We believe that the biggest influence lies with the prescriberinstitutional 'standard practice'. Education of these prescribing clinicians regarding the risk profile of opioids is key to reducing their use following surgery, thus lowering long-term opioid dependence.
\end{abstract}

Keywords: trauma; wrist; ankle; opioid; analgesia

\section{Introduction}

The USA and Canada have struggled with an 'opioid crisis' over the last few decades and have had to implement rigorous measures to monitor and regulate their prescription [1]. However, this issue is not unique to the North American continent; rates of opioid use and abuse are rising within the UK [2], with the issuing of prescriptions not always in line with best practice guidance $[3,4]$.

There is evidence that perioperative opioid use increases the risk of long-term opioid use [5-7], but there is limited evidence as to the 'correct' amount of analgesia a patient requires following certain orthopedic operations [8]. As a result, it has been suggested that 
the rationale behind opioid prescribing is often more to do with accepted practices and prescriber-dependent behavior than any true clinical reason $[9,10]$.

We hypothesized that opioid prescribing will be broadly similar across Scotland, with no links to any identifiable factor. Due to the high incidence of wrist and ankle trauma across the world, we chose to examine these injuries and their opioid use as a surrogate for opioid prescribing in the 'ambulatory' orthopedic population. Our primary outcome was to investigate new opioid prescriptions on discharge following surgical management of a wrist/ankle fracture. Secondary outcomes reviewed patient factors, injury, surgical and anesthetic variables that may influence post-operative prescribing patterns.

\section{Materials and Methods}

The study was conducted across six orthopedic trauma units under the Scottish Orthopedic Research Collaborative (SCORE), encompassing five health boards and four major trauma centers. All regions are involved in the post-graduate training of doctors across Scotland. The hospitals included Aberdeen, Dundee, Edinburgh, Inverness, Paisley, and Glasgow. Local health board approval was sought for each region.

Inclusion criteria: $>16$ years of age with closed physes and isolated (the only injury location) fracture of their distal radius or ankle requiring surgical management in the form of plate fixation. Ankle fractures could be of any type, including bimalleolar and trimalleolar. Exclusion criteria: polytrauma, pediatric patients, injuries managed non-operatively, and injuries managed with surgical techniques other than plate fixation (external fixation, K-wire fixation, etc.). All included were operated on within the year 2020.

Patients were identified from theater records. Electronic health records were reviewed to retrieve demographic data including pre-injury opioid use and history of anxiety/depression (as coded in their past medical history), both previously shown to increase the risk of higher post-operative opioid requirements [11,12]. Surgical procedure (number of incisions), anesthetic type (general vs. regional), ASA grade (a marker of comorbidity), length of stay, and discharge prescription/opioid type (strong opioids, e.g., morphine and oxycodone, or weak opioids, e.g., dihydrocodeine and codeine) were also recorded. The hospital picture archiving and communication (PACS) system was used to determine the AO fracture type. Briefly for wrists, type A: extra-articular, not involving the joint surface; type B: partial articular, with the fracture involving one part of the articular surface and the remainder of the joint remaining attached to the metaphysis/diaphysis; type C: intra-articular, with the fracture disrupting the joint surface and completely separating it from the diaphysis. For ankles, type A: infrasyndesmotic, type B: trans-syndesmotic, type C: suprasyndesmotic, all with reference to the lateral malleolus $+/-$ medial $(\mathrm{A} / \mathrm{B} / \mathrm{C})$ or posterior $(\mathrm{B} / \mathrm{C})$ lesions. Mechanism of injury was graded high if it was more than a mechanical fall from standing height (irrespective of activity performed; for example, team sports would be low energy and motor vehicle accident high energy). All supervising surgeons judged the reduction of the fracture to be satisfactory, and there were no cases revised for malreduction during the study period.

Ankle fracture patients and distal radius fracture patients were analyzed as two distinct groups. The continuous variable 'patient age' is presented as the median and range. Categorical variables are presented as frequencies and percentages. Data analysis was performed using SPSS version 22 (SPSS Inc., Chicago, IL, USA), with $p<0.05$ used as identifying significance.

A sample size was calculated to reach a precision of $10 \%$ in the estimation of the incidence of new opioid treatment as the primary outcome. According to Young et al., the expected incidence of opioid prescription may range between $40 \%$ and $90 \%$ for ankle fracture (depending on the country) and 30\% and $85 \%$ for wrist fracture, with differences of more than $20 \%$ between countries [13]. In the current study, a sample size of 50 patients per center, with an expected frequency of new opioid treatment of $85 \%$, would thus allow us to calculate $95 \%$ confidence intervals between $75 \%$ and $95 \%$ and to unmask differences beyond these $95 \%$ CIs with $p<0.05$. 
Descriptive analyses are the most important part of the study. Results are presented per individual center and in total.

The characteristics of each of the hospital cohorts were compared using the KruskalWallis test for continuous variables (age) and ordinal variables (fracture type, length of stay) and the chi-square test for categorical variables (gender, history of anxiety/depression, pre-injury prescription opioid use, anesthetic type, surgical approaches used). Primary outcome analysis was performed by comparing observed and expected frequencies of the presence or absence of a post-operative opioid prescription between cohorts using the chi-square test.

Regression analysis was used to examine our secondary outcomes. We performed bivariate analysis to identify the association of independent variables with the dependent variable of interest (post-operative opioid prescription). The Mann-Whitney $U$ test and the chi-square test were used for continuous and categorical variables, respectively.

Independent variables with $p<0.1$ or better were selected for inclusion in the regression analysis. We selected a binary logistic regression model to analyze the ability of the independent variables to influence the dependent variable, accounting for confounding. This produced the Nagelkerke R square, which provides an approximation of the proportion of variation in the dependent variable that can be explained by the independent variables. In addition, the model output produces the exponentiation of the B coefficient, $\operatorname{Exp}(B)$, for each independent variable included. The $\operatorname{Exp}(B)$ is an odds ratio, representing the effect that a one-unit increase in the independent variable has upon the odds of producing the dependent outcome: each unit increase in " $\mathrm{X}$ " multiplies the odds of "Y outcome" by $\operatorname{Exp}(B)$.

\section{Results}

A total of 598 patients were included in this retrospective cohort study, all of whom had received surgical management of an isolated acute distal radius (298) or ankle (300) fracture.

Table 1 shows the distal radius fracture cohort demographics. Median age, gender, rates of depression/anxiety, and pre-injury opioid use were similar across the six sites. Aberdeen and Glasgow had increased rates of pre-injury chronic pain diagnoses $(p=0.023)$, and Glasgow had increased use of neuropathic agents pre-injury $(p=0.004)$. AO fracture type, length of stay, and anesthetic practice were variable across all six groups $(p<0.001)$. High-energy mechanisms of injury were rarer in Dundee and Edinburgh $(p=0.014)$, and only Aberdeen and Edinburgh used dual approaches for a select few $(p=0.003)$.

Table 1. Distal radius fracture cohort demographics.

\begin{tabular}{|c|c|c|c|c|c|c|c|}
\hline Distal Radius & $\begin{array}{l}\text { Aberdeen } \\
\quad(50)\end{array}$ & $\begin{array}{l}\text { Dundee } \\
(49)\end{array}$ & $\begin{array}{l}\text { Edinburgh } \\
(49)\end{array}$ & $\begin{array}{l}\text { Inverness } \\
\quad(50)\end{array}$ & $\begin{array}{l}\text { Paisley } \\
\text { (49) }\end{array}$ & $\begin{array}{l}\text { Glasgow } \\
(51)\end{array}$ & $p$ Value \\
\hline Age, median years (IQr) & $50(38-62)$ & $56(52-60)$ & $48(34-62)$ & $53(48-59)$ & $56(49-63)$ & $51(38-63)$ & $\begin{array}{c}0.613 \\
\text { Kruskal-Wallis }\end{array}$ \\
\hline \multicolumn{8}{|l|}{ Gender, $n(\%)$} \\
\hline Female & $33(66)$ & $42(86)$ & $34(69)$ & $42(84)$ & $39(80)$ & $37(73)$ & 0.112 \\
\hline Male & $17(34)$ & $7(14)$ & $15(31)$ & $8(16)$ & $10(20)$ & $14(27)$ & Chi square \\
\hline $\begin{array}{c}\text { Depression/anxiety, } n(\%) \\
\text { Yes }\end{array}$ & $10(20)$ & $9(18)$ & $8(16)$ & $10(20)$ & $10(20)$ & $10(20)$ & $\begin{array}{l}0.996 \\
\text { Chi square }\end{array}$ \\
\hline $\begin{array}{c}\text { Chronic pain, } n(\%) \\
\text { Yes }\end{array}$ & $7(14)$ & 0 & $1(2)$ & $4(8)$ & $4(8)$ & $8(16)$ & $\begin{array}{l}0.023 \\
\text { Chi square }\end{array}$ \\
\hline $\begin{array}{l}\text { Pre-injury neuropathic } \\
\text { medication, } n(\%)\end{array}$ & 0 & $1(2)$ & $3(6)$ & $4(8)$ & $5(10)$ & $10(20)$ & $\begin{array}{l}0.004 \\
\text { Chi square }\end{array}$ \\
\hline \multicolumn{8}{|l|}{ Pre-injury opioid use, $n(\%)$} \\
\hline strong & 0 & $2(4)$ & $1(2)$ & 0 & $1(2)$ & $1(2)$ & 0.274 \\
\hline weak & $4(8)$ & $3(6)$ & $4(8)$ & $2(4)$ & $8(16)$ & $4(8)$ & Chi square \\
\hline \multicolumn{8}{|l|}{ Fracture type, $n(\%)$} \\
\hline A & $8(16)$ & $29(59)$ & $20(41)$ & $30(60)$ & $18(37)$ & $34(67)$ & $p<0.001$ \\
\hline B & $28(56)$ & $12(25)$ & $14(29)$ & $13(26)$ & $6(12)$ & $8(16)$ & Chi square \\
\hline $\mathrm{C}$ & $14(28)$ & $8(16)$ & $15(30)$ & $7(14)$ & $25(51)$ & $9(17)$ & \\
\hline
\end{tabular}


Table 1. Cont.

\begin{tabular}{|c|c|c|c|c|c|c|c|}
\hline Distal Radius & $\begin{array}{l}\text { Aberdeen } \\
\quad(50)\end{array}$ & $\begin{array}{c}\text { Dundee } \\
\text { (49) }\end{array}$ & $\begin{array}{l}\text { Edinburgh } \\
\quad(49)\end{array}$ & $\begin{array}{l}\text { Inverness } \\
\quad(50)\end{array}$ & $\begin{array}{l}\text { Paisley } \\
\text { (49) }\end{array}$ & $\begin{array}{c}\text { Glasgow } \\
(51)\end{array}$ & $p$ Value \\
\hline $\begin{array}{c}\text { High energy, } n(\%) \\
\text { Yes }\end{array}$ & $11(22)$ & $2(4)$ & $3(6)$ & $13(26)$ & $9(18)$ & $9(18)$ & $\begin{array}{c}0.014 \\
\text { Chi square }\end{array}$ \\
\hline $\begin{array}{l}\text { Anesthesia used, } n(\%) \\
\text { General only } \\
\text { Regional only } \\
\text { General plus regional } \\
\text { Missing value }\end{array}$ & $\begin{array}{l}36(78) \\
6(12) \\
5(10)\end{array}$ & $\begin{array}{c}20(41) \\
28(57) \\
0 \\
1(2)\end{array}$ & $\begin{array}{c}5(10) \\
0 \\
44(90)\end{array}$ & $\begin{array}{c}49(98) \\
1(2) \\
0\end{array}$ & $\begin{array}{c}43(88) \\
4(8) \\
2(4)\end{array}$ & $\begin{array}{l}21(41) \\
25(49) \\
5(10)\end{array}$ & $\begin{array}{c}p<0.001 \\
\text { Chi square }\end{array}$ \\
\hline $\begin{array}{c}\text { Surgical approaches, } n(\%) \\
\text { Single } \\
\text { Dual }\end{array}$ & $\begin{array}{l}45(90) \\
5(10)\end{array}$ & $\begin{array}{c}49(100) \\
0\end{array}$ & $\begin{array}{c}47(96) \\
2(4)\end{array}$ & $\begin{array}{c}50(100) \\
0\end{array}$ & $\begin{array}{c}49(100) \\
0\end{array}$ & $\begin{array}{c}51(100) \\
0\end{array}$ & $\begin{array}{c}p=0.003 \\
\text { Chi square }\end{array}$ \\
\hline $\begin{array}{c}\text { Length of stay, days }(\%) \\
\text { Same day } \\
1 \text { day } \\
2 \text { or more days }\end{array}$ & $\begin{array}{c}25(50) \\
22(44) \\
3(6)\end{array}$ & $\begin{array}{l}33(68) \\
8(16) \\
8(16)\end{array}$ & $\begin{array}{l}41(84) \\
5(10) \\
3(6)\end{array}$ & $\begin{array}{l}18(36) \\
25(50) \\
7(14)\end{array}$ & $\begin{array}{l}11(22) \\
25(51) \\
13(27)\end{array}$ & $\begin{array}{c}20(39) \\
29(57) \\
2(4)\end{array}$ & $\begin{array}{c}p<0.001 \\
\text { Chi square }\end{array}$ \\
\hline
\end{tabular}

Table 2 shows the ankle fracture cohort demographics. No significant difference was observed in median age, gender, rates of depression/anxiety and chronic pain diagnoses, pre-injury neuropathic or opioid analgesic use, fracture type, and energy of injury mechanism. A significant difference was observed in anesthetic practice $(p<0.001)$, number of approaches used during surgery $(p=0.040)$, and length of stay $(p<0.001)$.

Table 2. Ankle fracture cohort demographics.

\begin{tabular}{|c|c|c|c|c|c|c|c|}
\hline Ankles & $\begin{array}{l}\text { Aberdeen } \\
\quad(50)\end{array}$ & $\begin{array}{c}\text { Dundee } \\
(51)\end{array}$ & $\begin{array}{c}\text { Edinburgh } \\
(50)\end{array}$ & $\begin{array}{l}\text { Inverness } \\
\quad(50)\end{array}$ & $\begin{array}{l}\text { Paisley } \\
\text { (51) }\end{array}$ & $\begin{array}{c}\text { Glasgow } \\
(48)\end{array}$ & $p$ Value \\
\hline $\begin{array}{l}\text { Age, median years } \\
\text { (Interquartile Range) }\end{array}$ & $46(30-70)$ & $\begin{array}{c}56 \\
(40-64)\end{array}$ & $53(37-64.5)$ & $57(47-67)$ & $50(32-64)$ & $\begin{array}{c}48.5 \\
(35-60.5)\end{array}$ & $\begin{array}{c}0.219 \\
\text { Kruskal-Wallis }\end{array}$ \\
\hline \multicolumn{8}{|l|}{ Gender, $n(\%)$} \\
\hline Female & 25 & 34 & 35 & 32 & 37 & 31 & 0.235 \\
\hline Male & 25 & 17 & 15 & 18 & 14 & 17 & Chi square \\
\hline \multicolumn{8}{|l|}{ Depression/anxiety, $n(\%)$} \\
\hline No & 31 & 35 & 36 & 36 & 38 & 39 & 0.334 \\
\hline Yes & 19 & 16 & 14 & 14 & 13 & 8 & Chi square \\
\hline \multicolumn{8}{|l|}{ Chronic pain, $n(\%)$} \\
\hline No & 48 & 47 & 45 & 46 & 44 & 42 & 0.659 \\
\hline Yes & 2 & 4 & 5 & 4 & 7 & 5 & Chi square \\
\hline \multicolumn{8}{|l|}{$\begin{array}{l}\text { Pre-injury neuropathic } \\
\text { medication, } n(\%)\end{array}$} \\
\hline No & 46 & 47 & 49 & 46 & 43 & 42 & 0.279 \\
\hline Yes & 4 & 4 & 1 & 4 & 8 & 5 & Chi square \\
\hline \multicolumn{8}{|l|}{ Pre-injury opioid use, $n(\%)$} \\
\hline $\begin{array}{l}\text { Strong } \\
\text { Stron }\end{array}$ & 46 & 45 & 42 & 45 & 43 & 44 & 0.698 \\
\hline Weak & 4 & 6 & 8 & 5 & 8 & 4 & Chi square \\
\hline \multicolumn{8}{|l|}{ Fracture type, $n(\%)$} \\
\hline $\mathrm{A}$ & 5 & 3 & 3 & 9 & 7 & 3 & \\
\hline $\mathrm{B}$ & 31 & 38 & 26 & 29 & 29 & 34 & $p=0.137$ \\
\hline $\mathrm{C}$ & 14 & 10 & 21 & 12 & 15 & 11 & Chi square \\
\hline High energy, $n(\%)$ & 3 & 4 & 0 & 5 & 6 & 5 & $\begin{array}{c}0.264 \\
\text { Chi square }\end{array}$ \\
\hline \multicolumn{8}{|l|}{ Anesthesia used, $n(\%)$} \\
\hline General only & 24 & 13 & 7 & 29 & 30 & 14 & $p<0.001$ \\
\hline Spinal only & 24 & 25 & 11 & 18 & 8 & 28 & Chi square \\
\hline One of above, plus regional & 2 & 12 & 32 & 3 & 11 & 5 & \\
\hline (Missing value) & & 1 & & & 2 & 1 & \\
\hline \multicolumn{8}{|l|}{ Surgical approaches, $n(\%)$} \\
\hline Single & 21 & 28 & 18 & 23 & 23 & 32 & $p=0.040$ \\
\hline Dual & 29 & 23 & 32 & 27 & 28 & 16 & Chi square \\
\hline \multicolumn{8}{|l|}{ Length of stay, days (\%) } \\
\hline Same day & 6 & 8 & 17 & 1 & 1 & 5 & $p<0.001$ \\
\hline 1 day & 21 & 8 & 17 & 18 & 10 & 23 & Chi square \\
\hline 2 or more days & 23 & 35 & 16 & 31 & 40 & 20 & \\
\hline
\end{tabular}




\subsection{Opioid Prescribing Practice per Region}

Aberdeen, Inverness, Edinburgh, and Glasgow favored dihydrocodeine $30 \mathrm{mg}$ four times daily for pain (28-tablet packs). Dundee and Paisley favored co-codamol. Strong opioids favored across the nation were either additional oral morphine sulfate solution $10 \mathrm{mg} / 5 \mathrm{~mL} 2-4$ hourly as required for pain, $100 \mathrm{~mL}$ bottle, or a small supply of immediaterelease oxycodone $5 \mathrm{mg} 2-4$ hourly as required for pain ( 28 pack). No patients were discharged on new sustained-release opioids.

\subsection{Distal Radius Fracture Cohort}

Across the 298 patients, 255 (85.6\%) patients received a new discharge opioid prescription, of which 240 (80.5\%) patients received a weak opioid prescription, and 15 (5.0) received a strong opioid prescription (Table 3 ). Prescription rates did not vary significantly $(p=0.407)$. One patient from the Glasgow cohort had missing data.

Table 3. Rates of post-operative opioid prescription in the distal radius fracture cohort.

\begin{tabular}{|c|c|c|c|c|c|c|c|}
\hline & Aberdeen & Dundee & Edinburgh & Inverness & Paisley & Glasgow & $p$ Value \\
\hline \multicolumn{8}{|l|}{$\begin{array}{l}\text { Post-operative opioid } \\
\text { prescription, } n(\%)\end{array}$} \\
\hline Strong & & & & & & 0 & \\
\hline Weak & 1 & 5 & 3 & 4 & 2 & 43 & \\
\hline None & 45 & 35 & 40 & 38 & 39 & 7 & $p=0.407$ \\
\hline (Missing values) & 4 & 9 & 6 & 8 & 8 & 1 & Chi square \\
\hline
\end{tabular}

Univariate analysis (Table 4) identified no single variable as a causative factor for opioid prescription, with only AO fracture type A approaching significance $(p=0.088)$.

Table 4. Univariate analysis of wrist fracture cohort.

\begin{tabular}{|c|c|c|c|}
\hline & No Opioid (N) & Opioid (N) & $p$ Value \\
\hline Age & Median $=60.5$ & Median $=60$ & $\begin{array}{c}0.750 \\
\text { Mann-Whitney U test }\end{array}$ \\
\hline $\begin{array}{l}\text { Location } \\
\text { Aberdeen } \\
\text { Dundee } \\
\text { Edinburgh } \\
\text { Inverness } \\
\text { Paisley } \\
\text { Glasgow }\end{array}$ & $\begin{array}{l}4 \\
9 \\
6 \\
8 \\
8 \\
7\end{array}$ & $\begin{array}{l}46 \\
40 \\
43 \\
42 \\
41 \\
43\end{array}$ & $\begin{array}{l}0.738 \\
\text { Chi square }\end{array}$ \\
\hline $\begin{array}{l}\text { Gender } \\
\text { Female } \\
\text { Male }\end{array}$ & $\begin{array}{c}34 \\
8\end{array}$ & $\begin{array}{c}192 \\
63\end{array}$ & 0.426 \\
\hline $\begin{array}{c}\text { Depression/Anxiety } \\
\text { Diagnoses } \\
\text { No } \\
\text { Yes }\end{array}$ & $\begin{array}{c}37 \\
5\end{array}$ & $\begin{array}{c}203 \\
52\end{array}$ & 0.196 \\
\hline $\begin{array}{c}\text { Chronic Pain } \\
\text { Diagnosis } \\
\text { No } \\
\text { Yes }\end{array}$ & $\begin{array}{c}39 \\
3\end{array}$ & $\begin{array}{c}235 \\
20\end{array}$ & 0.875 \\
\hline $\begin{array}{c}\text { Pre-Injury } \\
\text { Neuropathic Agent } \\
\text { Use } \\
\text { No } \\
\text { Yes }\end{array}$ & $\begin{array}{c}39 \\
3\end{array}$ & $\begin{array}{c}236 \\
19\end{array}$ & 0.944 \\
\hline
\end{tabular}


Table 4. Cont.

\begin{tabular}{cccc}
\hline & No Opioid (N) & Opioid (N) & $p$ Value \\
\hline $\begin{array}{c}\text { Pre-Injury Opioid Use } \\
\text { No }\end{array}$ & 39 & 229 & \\
Yes & 3 & 26 & 0.537 \\
\hline Fracture Type & & & \\
A & 13 & 125 & 0.088 \\
B & 14 & 67 & Near significance \\
C & 15 & 63 & \\
Use of Regional Block & & & 0.691 \\
No & 24 & 154 & \\
Yes & 18 & 101 &
\end{tabular}

The binary logistic regression model accounted for only $3 \%$ of the variability in postoperative opioid prescribing (Nagelkerke R square, $p<0.001$ ) and included only fracture type as a statistically significant predictor. Using type $C$ fractures as the reference, patients with a type $\mathrm{A}$ fracture were more likely to receive an opioid prescription $(\operatorname{Exp}[\mathrm{B}]=2.3$, $95 \% \mathrm{CI}=1.0-5.2, p=0.04)$.

\subsection{Ankle Fracture Cohort}

Across the 300 patients, $248(82.7 \%)$ patients received a new discharge opioid prescription, of which 197 (65.7) were for a weak opioid, and 51 (17.0\%) were for a strong opioid (Table 5). Rates and strength of prescription varied significantly, with Dundee and Edinburgh using significantly more strong opioids in addition to their weak opioids and Inverness and Paisley giving the least discharge opioid prescriptions overall.

Table 5. Rates of post-operative opioid prescription in the ankle fracture cohort.

\begin{tabular}{cccccccc}
\hline & Aberdeen & Dundee & Edinburgh & Inverness & Paisley & Glasgow & $p$ Value \\
\hline $\begin{array}{c}\text { Post-operative opioid } \\
\text { prescription, } n \text { (\%) }\end{array}$ & & & & & & & \\
Strong & 1 & 16 & 17 & 7 & 6 & 4 & \\
Weak & 42 & 29 & 29 & 27 & 33 & 37 & Chi square \\
None & 7 & 6 & 4 & 16 & 12 & 7 & \\
\hline
\end{tabular}

Univariate analysis (Table 6$)$ revealed younger age $(p<0.001)$, location $(p=0.018)$ and longer length of stay $(p=0.018)$ as predictors of receiving a discharge opioid prescription. Pre-injury neuropathic agent use approached significance $(p=0.060)$.

Using any opioid discharge prescription as the dependent variable, the binary logistic regression model accounted for $23 \%$ of the variability in post-operative opioid prescribing (Nagelkerke R square, $p<0.001$ ) and correctly classified $82 \%$ of cases. It included patient age, patient location, and length of stay as statistically significant predictors. For every one-year increase in age, patients were $3 \%$ less likely to receive an opioid prescription $(\operatorname{Exp}[B]=0.97$, $95 \% \mathrm{CI}=0.94-0.98, p<0.001)$. When compared with Edinburgh, patients in Inverness $(\operatorname{Exp}[\mathrm{B}]=0.17,0.04-0.59, p=0.01)$ were less likely to receive an opioid prescription. When compared with patients staying 1 day, same-day discharges (i.e., 0 days) were less likely to receive an opioid $(\operatorname{Exp}[\mathrm{B}]=0.14,0.04-0.51, p=0.003)$. Patients staying 2 or more days were also less likely to receive a discharge opioid prescription than those staying 1 day $(\operatorname{Exp}[\mathrm{B}]=0.25,0.08-0.66, p=0.009)$. 
Table 6. Univariate analysis of ankle fracture cohort.

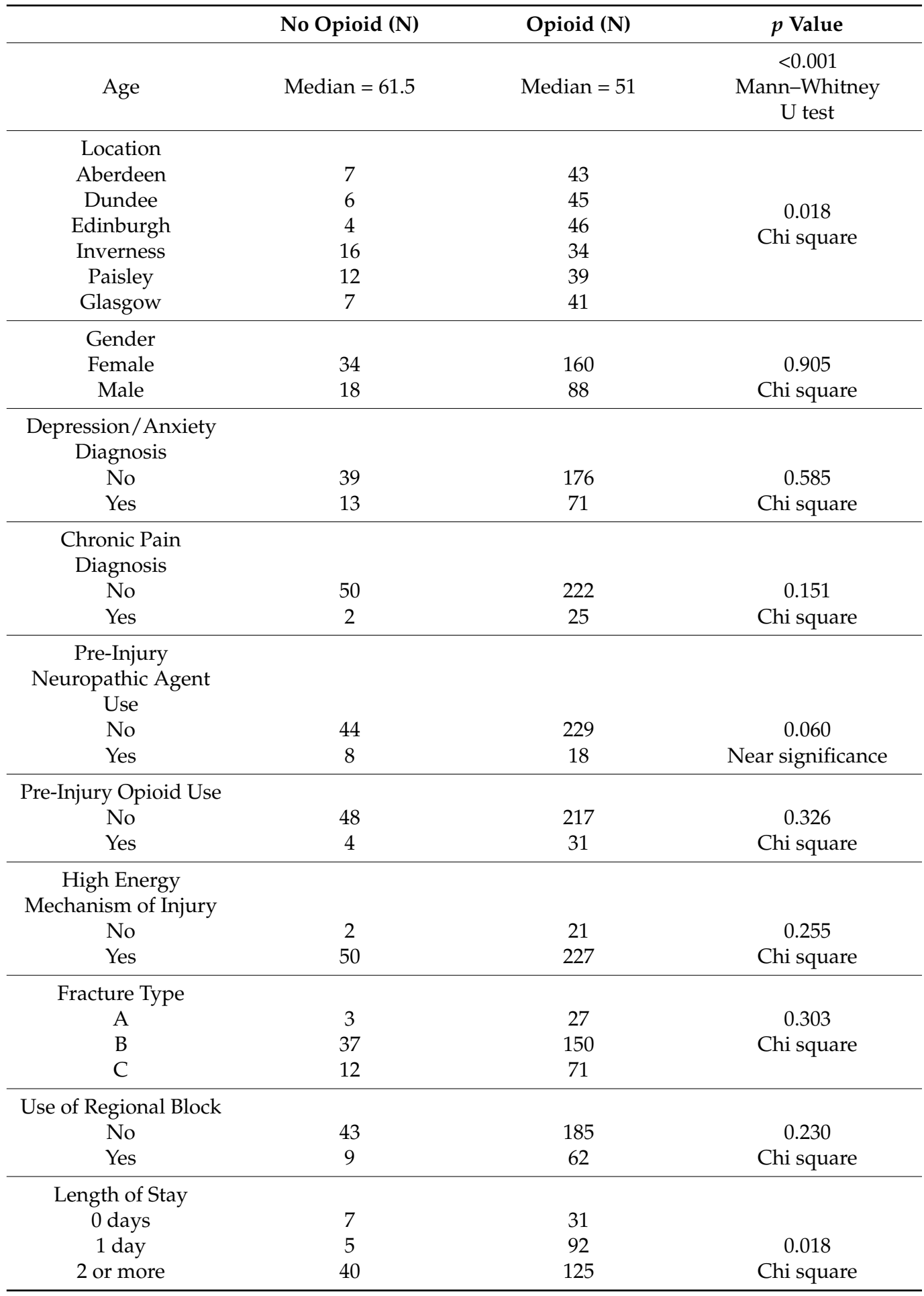

Using a strong opioid discharge prescription as the dependent variable, the model accounted for $26 \%$ of the variability in strong opioid prescribing (Nagelkerke R square, $p<0.001$ ), and correctly classified $83 \%$ of cases. It included patient location, pre-injury use of neuropathic medications, and length of stay as significant predictors. When compared with Aberdeen, patients in Dundee $(\operatorname{Exp}[\mathrm{B}]=26.7,5.1-467.3, p=0.002)$ and Edinburgh $(\operatorname{Exp}[\mathrm{B}]=53.2,9.3-565.0, p<0.001)$ were more likely to receive a strong opioid. Pre-injury use of neuropathic analgesic agents increased the odds of a strong opioid script by a magnitude of $4.3(\operatorname{Exp}[\mathrm{B}], 95 \% \mathrm{CI}=1.4-10.6, p=0.007)$. When compared with patients 
staying 1 day, same-day discharges (i.e., 0 days) were less likely to receive an opioid $(\operatorname{Exp}[\mathrm{B}]=0.16,0.03-0.63, p=0.02)$. Including the use of regional blocks had no effect on the models.

\section{Discussion}

This study shows significant variability in the patients, injuries, and perioperative practices when considering those that undergo distal radius fracture fixation across Scotland. Despite this, opioid analgesic prescription on discharge remains very consistent, with $85 \%$ of patients receiving new opioids. Of the patients in the distal radius cohort, $80 \%$ receive new weak opioids on discharge. Strong opioid prescription on discharge following a distal radius fracture was infrequent.

When considering the ankle fracture cohort, patient demographics and injury selection for surgical intervention are generally consistent across Scotland, but anesthetic and surgical practices do show some variation, along with length of stay post-operatively. Strength of opioids prescribed on discharge varied significantly, with Dundee and Edinburgh giving additional strong opioids as required on top of weak opioids and Inverness using significantly fewer opioids overall. These centers did not otherwise vary significantly in the patient and operative characteristics within their cohorts.

In the United States of America, the term 'opioid crisis' has been coined, with work being done to monitor and regulate opioid prescription. There is increasing concern that this crisis is spreading to Europe [1]. American research identified the three most important prescription factors influencing long-term opioid use as the use of modified-release opioids, repeat prescription following discharge, and the size of the initial prescription given $[14,15]$. Within the UK, as evidenced by our results, we favor weak opioids such as dihydrocodeine/co-codamol, and the rate of their use (and therefore risk of misuse) has increased significantly over the last decade $[2,16]$. Although our patients are supplied with a relatively small quantity of opioids following their operation by the hospital, the recent meta-analysis by Lawal et al. (2020) [11] involving over 1.9 million patients showed that $7 \%$ of patients continue to request opioid analgesia prescriptions more than 3 months after surgery, which if applied to our cohort alone is 41 patients-a noteworthy proportion, even if the generalizability of this remains debatable.

Scottish wrist fracture discharge opioid practices are broadly similar across the country. AO fracture type A showed a significant relationship with increasing opioid prescription, a finding not easily explained after controlling for the influence of other variables.

When examining the ankle cohort, younger age and pre-injury use of neuropathic agents showed an association with opioid discharge prescription. Length of stay was also a factor, with patients staying 1 night only receiving the most opioid prescriptions on discharge, although this may be linked to perception from the prescriber. If the patient goes home the same day, then they may be perceived to be 'less sore', and those staying multiple days being weaned off their opioids, or alternatively, being the older, frailer subgroup. An ambulating patient, remaining opioid naïve until discharge, may be seen as less suitable for opioids due to them being more at risk of toxicity or less at risk of needing them.

None of the variables examined in the wrist cohort except for AO type A fractures appear to have any individual effect on discharge opioid prescription rates, especially relevant considering the variation in practice across the six units studied. Other factors must be influencing opioid prescribing, namely prescriber culture and institutional practices. This has been researched previously [17-19], predominantly in the USA. Education of doctors-intraining is key to highlighting the dangers of opioid prescription, which might reduce the widespread practice of using opioids as the mainstay of post-operative pain control. Patient perceptions of pain and nociception may play a role; managing the pain expectations of patients post-operatively has the potential to reduce the perceived requirement for opioids [20].

Daliya et al. [3] performed a similar study within the UK, reviewing prescribing patterns on discharge following elective general surgical procedures. Their study highlighted 
a lack of guidance and education amongst medical staff, with a requirement for improved opioid stewardship at individual institutional levels. Our study suggests a similar issue within the orthopedic trauma setting through the prescribing practices currently occurring.

Higgins et al. [21] examined iatrogenic opioid dependence in patients prescribed opioids for chronic pain and reported a rate of $4.7 \%$. They identify opioids within the weak category as being associated with a higher risk of long-term dependence/abuse, a concern when considering the discharge prescriptions within our trauma population.

Our regression models identified that the included variables accounted for 3\% (wrists) and 23\% (ankles) of variation, respectively. This supports our theory that other factors, namely institutional 'standard practice', are involved. We only included injuries managed surgically using standard internal fixation techniques, excluding external fixation, in order to try and standardize our patient cohort to ambulant patients with high-incidence injuries not requiring subspecialty interventions. Although we did not include all socioeconomic factors, we attempted to cover anxiety/depression diagnoses and pre-injury opioid use, two of the main factors shown to most influence the prescription of opioids post-operatively $[20,22]$. We have also not considered perioperative and inpatient opioid prescription $[23,24]$. The ongoing coronavirus pandemic will have inevitably influenced anesthetic practices [25]; however, this does not appear to have influenced discharge prescriptions. For this study, we have no data on analgesic consumption or any additional prescriptions provided in primary care due to the lack of crossover between primary and secondary care records in the UK.

\section{Conclusions}

This Scottish national multicenter study examining opioid analgesia prescription following wrist or ankle fracture surgery suggests the biggest influence on prescription practices lies with the prescriber rather than the patient. There are some links with younger age, pre-injury neuropathic use, and length of stay, but it is impossible to ignore the overwhelming influence of institutional 'standard practice'.

Education of healthcare staff and patients is key to reducing the use of opioids following surgery, thus lowering the risk of their long-term use. Further prospective research will look to understand patient experiences and outcomes with respect to the analgesics they were provided with, to accurately stratify and validate analgesic practices in a patientspecific way.

Supplementary Materials: The following are available online at https://www.mdpi.com/article/ 10.3390/jcm11020468/s1, Membership of the Score Collaborators.

Author Contributions: Conceptualization, W.T.G., P.F., S.A.A. and I.M.S.; methodology, W.T.G., D.R.W.M., M.J.K., A.C.F., J.R.M., P.F., S.A.A. and I.M.S.; software, W.T.G. and S.A.A.; validation, W.T.G. and I.M.S.; formal analysis, S.A.A.; investigation, W.T.G., D.R.W.M., M.J.K., A.C.F. and J.R.M.; writing—original draft preparation, W.T.G.; writing—review and editing, W.T.G., D.R.W.M., P.F., S.A.A. and I.M.S.; visualization, W.T.G., S.A.A. and I.M.S.; supervision, I.M.S.; project administration, W.T.G. All members of the SCORE collaborative mentioned in the supplementary material were involved in the data collection and organisation at each collaborating site, coordinated by the named author based at that site. All authors have read and agreed to the published version of the manuscript.

Funding: This research received no external funding.

Institutional Review Board Statement: Not applicable.

Informed Consent Statement: Patient consent was waived due to this being a retrospective case note review with anonymized summary data only being presented.

Data Availability Statement: The data presented in this study are available on request from the corresponding author. The data are not publicly available due to the details of the injuries being potentially patient identifiable.

Conflicts of Interest: The authors declare no conflict of interest. 


\section{References}

1. Helmerhorst, G.T.; Teunis, T.; Janssen, S.J.; Ring, D. An epidemic of the use, misuse and overdose of opioids and deaths due to overdose, in the United States and Canada: Is Europe next? Bone Joint J. 2017, 99, 856-864. [CrossRef]

2. Giraudon, I.; Lowitz, K.; Dargan, P.I.; Wood, D.M.; Dart, R.C. Prescription opioid abuse in the UK. Br. J. Clin. Pharmacol. 2013, 76, 823-824. [CrossRef]

3. Daliya, P.; Adiamah, A.; Roslan, F.; Theophilidou, E.; Knaggs, R.D.; Levy, N.; Lobo, D.N. Opioid prescription at postoperative discharge: A retrospective observational cohort study. Anaesthesia 2021, 76, 1367-1376. [CrossRef]

4. Mordecai, L.; Reynolds, C.; Donaldson, L.J.; de C Williams, A.C. Patterns of regional variation of opioid prescribing in primary care in England: A retrospective observational study. Br. J. Gen. Pract. 2018, 68, e225-e233. [CrossRef]

5. Hah, J.M.; Bateman, B.T.; Ratliff, J.; Curtin, C.; Sun, E. Chronic Opioid Use After Surgery: Implications for Perioperative Management in the Face of the Opioid Epidemic. Anesth. Analg. 2017, 125, 1733-1740. [CrossRef]

6. Gossett, T.D.; Finney, F.T.; Hu, H.M.; Waljee, J.F.; Brummett, C.M.; Walton, D.M.; Holmes, J.R. New Persistent Opioid Use and Associated Risk Factors Following Treatment of Ankle Fractures. Foot Ankle Int. 2019, 40, 1043-1051. [CrossRef]

7. Forget, P. Opioid-free anaesthesia. Why and how? A contextual analysis. Anaesth. Crit. Care Pain Med. 2019, 38, 169-172. [CrossRef]

8. Spinarelli, A.; Moretti, L.; Marella, G.; Solarino, G.; Maccagnano, G.; Moretti, B. Pain management after total knee arthroplasty: The good, the bad and the ugly. J. Biol. Regul. Homeost. Agents 2015, 29 (Suppl. S4), 131-135. [PubMed]

9. Leventhal, E.L.; Nathanson, L.A.; Landry, A.M. Variations in Opioid Prescribing Behavior by Physician Training. West J. Emerg. Med. 2019, 20, 428-432. [CrossRef] [PubMed]

10. Kelly, S.; Johnson, G.T.; Harbison, R.D. "Pressured to prescribe" The impact of economic and regulatory factors on South-Eastern ED physicians when managing the drug seeking patient. J. Emerg. Trauma Shock 2016, 9, 58-63. [PubMed]

11. Lawal, O.D.; Gold, J.; Murthy, A.; Ruchi, R.; Bavry, E.; Hume, A.L.; Lewkowitz, A.K.; Brothers, T.; Wen, X. Rate and Risk Factors Associated with Prolonged Opioid Use After Surgery: A Systematic Review and Meta-analysis. JAMA Netw. Open 2020, 3, e207367. [CrossRef] [PubMed]

12. Woo, A.K. Depression and Anxiety in Pain. Rev. Pain 2010, 4, 8-12. [CrossRef] [PubMed]

13. Young, J.D.; Bhashyam, A.R.; Qudsi, R.A.; Parisien, R.L.; Shrestha, S.; Van der Vliet, Q.M.; Fils, J.; Losina, E.; Dyer, G.S. CrossCultural Comparison of Postoperative Discharge Opioid Prescribing After Orthopaedic Trauma Surgery. J. Bone Joint Surg. Am. 2019, 101, 1286-1293. [CrossRef]

14. Shah, A.; Hayes, C.J.; Martin, B.C. Characteristics of initial prescription episodes and likelihood of long-term opioid use-United States, 2006-2015. MMWR Morb. Mortal. Wkly. Rep. 2017, 66, 265-269. [CrossRef]

15. Deyo, R.A.; Hallvik, S.E.; Hildebran, C.; Marino, M.; Dexter, E.; Irvine, J.M.; O'Kane, N.; Van Otterloo, J.; Wright, D.A.; Leichtling, G.; et al. Association between initial opioid prescribing patterns and subsequent long-term use among opioid-naïve patients: A statewide retrospective cohort study. J. Gen. Intern. Med. 2017, 32, 21-27. [CrossRef]

16. Jani, M.; Birlie Yimer, B.; Sheppard, T.; Lunt, M.; Dixon, W.G. Time trends and prescribing patterns of opioid drugs in UK primary care patients with non-cancer pain: A retrospective cohort study. PLoS Med. 2020, 17, e1003270. [CrossRef]

17. Bhashyam, A.R.; Young, J.; Qudsi, R.A.; Parisien, R.L.; Dyer, G.S. Opioid Prescribing Patterns of Orthopedic Surgery Residents After Open Reduction Internal Fixation of Distal Radius Fractures. J. Hand Surg. Am. 2019, 44, 201-207. [CrossRef]

18. Chiu, A.S.; Healy, J.M.; DeWane, M.P.; Longo, W.E.; Yoo, P.S. Trainees as Agents of Change in the Opioid Epidemic: Optimizing the Opioid Prescription Practices of Surgical Residents. J. Surg. Educ. 2018, 75, 65-71. [CrossRef] [PubMed]

19. Gaspar, M.P.; Pflug, E.M.; Adams, A.J.; Jacoby, S.M.; Shin, E.K.; Osterman, A.L.; Kane, P.M. Self-Reported Postoperative OpioidPrescribing Practices Following Commonly Performed Orthopaedic Hand and Wrist Surgical Procedures: A Nationwide Survey Comparing Attending Surgeons and Trainees. J. Bone Joint Surg. Am. 2018, 100, e127. [CrossRef] [PubMed]

20. Brown, L.E.; Fatehi, A.; Ring, D. Talking points for the safe and effective alleviation of pain. Bone Joint J. 2020, $102,1122-1127$. [CrossRef]

21. Higgins, C.; Smith, B.H.; Matthews, K. Incidence of iatrogenic opioid dependence or abuse in patients with pain who were exposed to opioid analgesic therapy: A systematic review and meta-analysis. Br. J. Anaesth. 2018, 120, 1335-1344. [CrossRef] [PubMed]

22. Curtis, H.J.; Croker, R.; Walker, A.J.; Richards, G.C.; Quinlan, J.; Goldacre, B. Opioid prescribing trends and geographical variation in England, 1998-2018: A retrospective database study. Lancet Psychiatry 2019, 6, 140-150. [CrossRef]

23. Quinlan, J.; Rann, S.; Bastable, R.; Levy, N. Perioperative opioid use and misuse. Clin. Med. 2019, 19, 441-445. [CrossRef]

24. Levy, N.; Quinlan, J.; El-Boghdadly, K.; Fawcett, W.J.; Agarwal, V.; Bastable, R.B.; Cox, F.J.; de Boer, H.D.; Dowdy, S.C.; Hattingh, K.; et al. An international multidisciplinary consensus statement on the prevention of opioid-related harm in adult surgical patients. Anaesthesia 2021, 76, 520-536. [CrossRef] [PubMed]

25. Velly, L.; Gayat, E.; Quintard, H.; Weiss, E.; De Jong, A.; Cuvillon, P.; Audibert, G.; Amour, J.; Beaussier, M.; Biais, M.; et al Guidelines: Anaesthesia in the context of COVID-19 pandemic. Anaesth. Crit. Care Pain Med. 2020, 39, 395-415. [CrossRef] [PubMed] 